\title{
EL USO DE JUEGOS TRADICIONALES EN EL. PROCESO EDUCATIVO Y SU DESVIRTUACIÓN EN LA PRAXIS PEDAGÓGICA
}

\author{
Joaquín Giró Miranda \\ Universidad de La Rioja
}

RESUMEN. Hoy día no resulta extraño que en las programaciones del magisterio nos encontremos con el uso de juegos tradicionales como medios de promoción educativa, como instrumentos de participación escolar, como técnicas de aprendizaje y desarrollo.

Pero quizás no nos hemos preguntado sobre el carácter y valor de esos juegos en su aplicación cotidiana en los centros escolares, cuando nosotros los describimos como tradicionales, pese a que su motivación inicial, su práctica original, ha desaparecido al aplicarle conceptos pedagógicos de utilidad y provecho.

Los intereses del profesorado toman como meta la búsqueda del provecho educativo; se mueven por la utilidad de las técnicas aplicadas, siempre con el afán pedagógico como motor que nos aproxima a las metas y objetivos propuestos. $Y$ este interés, este afán, estas metas, son las coordenadas que queremos destacar como opuestas a los intereses y objetivos del juego tradicional, los cuales trataremos de explicar.

ABSTRACT. Nowadays it is not strange we find traditional games as means of educative promotion, as tools to take part at school, as methods of learning and development in the curriculum of teaching.

Maybe we do not wonder about the value of those games in their daily use at schools, when we describe them as traditional, though their initial motivation, their original practice has disappeared when we apply them educational concepts of helpful and benefit.

The teachers interests pursue the aim of educational methods; they are moved by the useful of their methods, always with the educational aim as the engine to reach those objectives.

These interests are the focal point we want to underline as opposed to the interests of traditional games, which will try to explain.

\section{A modo de introducción}

Hace años nos encontrábamos dedicados a la búsqueda y recogida de objetos y materiales etnográficos en los valles Riojanos, con el fin de llevar a cabo oportunas comparaciones etnológicas que nos permitieran establecer algunas hipótesis acerca 
de los referentes que cimentaban la identidad riojana, y de ese modo entender algunos de los cambios sociales acaecidos por entonces.

De aquellos años conservo bastantes materiales con los que se pudo confeccionar alguna que otra monografía, pero quizás, por el volumen de los materiales, la gran participación de informantes y el exquisito cuidado que mantuvo su editor, fueron los juegos infantiles tradicionales de La Rioja, los que me proporcionaron mayor satisfacción creativa ${ }^{1}$.

Si anticipo estas experiencias vitales es porque no deseo provocar extrañeza con el tema que les propongo. Cuanto sigue no son sino reflexiones en voz alta acerca del significado del juego tradicional y su vinculación al proceso educativo. Algunas de ellas les resultarán obvias o conocidas, incluso no dudo que el tema resulte para algunos superfluo y poco interesante.

La hipótesis inicial que condujo a estas reflexiones, sugería que la utilización de los juegos tradicionales entre pedagogos y profesionales del magisterio, está en contradicción con la esencia definitoria de los mismos.

Hoy día no resulta extraño que en las programaciones del magisterio nos encontremos con el uso de juegos tradicionales como medios de promoción educativa, como instrumentos de participación escolar, como técnicas de aprendizaje y desarrollo.

En ocasiones podemos leer entre los objetivos que se marcan los proyectos curriculares, la recolección, investigación y adaptación de juegos populares o tradicionales a las programaciones de aula, como parte del engranaje educativo y, en ocasiones, sobre todo en la educación infantil, como parte crucial e indispensable del desarrollo de las unidades didácticas. Tales ejemplos son pauta común en los estudiantes de prácticas de magisterio, que asumen dicha labor sin más pretensión que la de utilizar una metodología y unas técnicas aprendidas durante su formación académica y que piensan someter a prueba con la certidumbre del éxito.

En el ámbito escolar, el juego aparece como un objetivo más en cualquier adaptación curricular al fomentar la socialización y la relación interpersonal, sin quedarse en el espíritu de la letra, sino plasmándolo en unas actividades concretas y no dejándolas al azar o a la buena voluntad del profesor tutor.

Pero quizás no nos hemos preguntado sobre el carácter y valor de esos juegos en su aplicación cotidiana en los centros escolares, cuando nosotros los describimos como tradicionales, pese a que su motivación inicial, su práctica original, ha desaparecido al aplicarle conceptos pedagógicos de utilidad y provecho

Y es que la reflexión acerca del método o las técnicas a utilizar no se produce si su aplicación repetitiva es sancionada de forma positiva por quienes tutorizan la labor educativa del magisterio. Si esa reflexión tuviera un carácter inequívoco sobre el valor atribuido a los juegos, nos faltaría tiempo para descubrir que aquello que por inercia denominamos popular o tradicional, no es sino una etiqueta que en nada refleja el auténtico dominio del juego tradicional.

Los intereses del profesorado toman como meta la búsqueda del provecho educativo; se mueven por la utilidad de las técnicas aplicadas, siempre con el afán pedagógico como motor que nos aproxima a las metas y objetivos propuestos. $Y$ este interés,

1. Joaquín Giro, "juegos infantiles de La Rioja", Ibercaja, Zaragoza 1990 
este afán, estas metas, son las coordenadas que queremos destacar como opuestas a los intereses y objetivos del juego tradicional, los cuales trataremos de explicar.

Sabemos que, en palabras de Château ${ }^{2}$, el papel pedagógico del juego no se limita a la adquisición de los datos útiles al pedagogo. El juego origina muchas actividades superiores, si es que no las origina a todas, arte, ciencia, trabajo, etc. Constituye, por consiguiente, como el vestíbulo natural de esas actividades; por su intermedio el niño puede llegar a ellas. Se concibe entonces que se haya podido buscar en el juego un medio de educación. Los métodos activos en educación han usado sin cesar y a veces abusado del juego. Conviene entonces ver, en qué sentido y hasta qué punto, el juego puede llevar al niño a las puertas de la vida social y hacerle conocer el trabajo.

Château está en lo cierto al prevenirnos sobre el uso abusivo del juego en la metodología educativa. Sobre todo, en cuanto estos métodos activos monopolizan casi en exclusiva los primeros años escolares del niño, desvirtuando en gran medida el fin ensimismado que poseen los juegos infantiles.

La pedagogía, durante mucho tiempo reservada en cuanto al provecho que se podía obtener del juego, debido al desvío de la atención que acompaña a sus manifestaciones, no se ha interesado verdaderamente por él mas que propalando la idea de que se podía "jugar con provecho". Esto explica quizá, por qué los juegos concebidos por los pedagogos -además de artificiosos- son con frecuencia tan poco atractivos. Comoquiera que sea, esta preocupación funcionalista se ha impuesto en el estudio del juego, echando a perder su comprensión.

\section{Juegos tradicionales, deportes y espectáculo de masas}

Se tiende a hablar indistintamente de juegos tradicionales, deportes autóctonos y deportes de masas como si fueran partes complementarias de un todo. $Y$, aunque en su origen pueda existir un tronco común, parece claro que en su desarrollo actual tienen poco que ver.

En primer lugar, los juegos tradicionales siguen penetrados del encanto primigenio, propio de ese tiempo sin tiempo que es la infancia, ajenos por ello a toda imposición o mandato. Por su parte, en los deportes autóctonos, aparecen normas que establecen ciertos controles, aunque éstas sean cambiantes no sólo en función de las modalidades, sino de las tierras y lugares donde se pongan en práctica; todo ello implica una riqueza de variantes y matices inherentes a otras muchas manifestaciones de la cultura tradicional.

Por el contrario, en los deportes de masas, propios de una sociedad dominada por los medios de comunicación, además de normas rígidas y controles estrictos -incluso extradeportivos- aparece un factor determinante como es el público, sin el cual se tambalea su razón de ser.

Es fácil colegir que en una sociedad orientada y en ocasiones guiada por los medios de comunicación, tanto los juegos tradicionales como los deportes autóctonos hayan cedido progresivamente protagonismo, llegando en algunos casos a temerse

2. Jean Château, "Psicología de los juegos infantiles", Buenos Aires 1973, pag.112 
por su desaparición, a pesar de todas las virtualidades, comunicación, espontaneidad, participación, creatividad, que encierran frente a los deportes de masas que convierten al público en pasivo espectador.

El deterioro y, en algunos casos, la desaparición de los juegos tradicionales, proviene de los profundos cambios sociales ocurridos en la primera mitad de este siglo, con el proceso de industrialización, las migraciones masivas desde el campo y el medio rural, y los cambios subsiguientes en la estructura familiar y en los usos sociales del tiempo libre, que llevaron a un desclasamiento de los juegos tradicionales, con lo que hasta entonces había sido el medio idóneo para su transmisión.

Si a ello sumamos la introducción de los deportes de masas y espectáculo, se observará el peligro nada metafórico, en que se vieron inmersos gran número de estos juegos y deportes tradicionales.

Fue el cambio sociopolítico ocurrido en España tras la promulgación del Estado de las Autonomías, el que llevó a un nuevo interés recurrente por los juegos y deportes tradicionales, sobre todo entre los artífices y diseñadores de la identidad cultural de los pueblos y regiones españolas, ya que entre los referentes de esas identidades, se integraban jcómo no; los juegos, lo que sirvió en definitiva para que se llevara una labor de rescate y promoción.

Traspasado el umbral de los primeros años de definición de las regiones y nacionalidades del Estado Español, la promoción de los juegos y deportes tradicionales se trasladó desde el espacio festivo y cultural, al espacio educativo y escolar, puesto que en dicho proyecto de promoción se persigue que las nuevas generaciones asuman el valor de la tradición para el mantenimiento de la identidad cultural y étnica. El ámbito escolar, como agencia de socialización preferente, debía cubrir el hueco abierto desde las instituciones sociales y políticas, en favor de una identidad comunitaria y la adquisición de los referentes necesarios para su mantenimiento

Los juegos tradicionales son definidos así, porque se proveen de referencias culturales insertas en el ámbito de un territorio o comunidad (no podemos olvidar que el juego se da en sociedades y culturas concretas y que cualquier intento de análisis del mismo debe partir del contexto cultural en el que se da), y participan de lo que en sociología denominamos proceso de socialización, y en antropología proceso de enculturación, o transmisión por las generaciones mayores, de normas, valores, creencias y hábitos compartidos, a las generaciones más jóvenes. La acción educadora de una generación sobre otra viene a ser el modo como se concreta, en una sociedad, la acción enculturadora de sus miembros adultos sobre los miembros jóvenes que han de incorporarse a ella.

El proceso de enculturación garantiza que cada nuevo miembro adoptará como propia la cultura del grupo, quedando programado para reproducir en todas las acciones de su vida cotidiana el comportamiento de las generaciones precedentes, incluido el proceder enculturativo para con sus descendientes. A la vez, el proceso enculturativo asegura la permanencia de la cultura de un grupo, de modo que aquellos contenidos culturales (véase entre otros, los juegos y deportes tradicionales), transmitidos de generación en generación por el aprendizaje, son la cultura específica de ese grupo.

Si los referentes culturales de la tradición encontraban en el marco festivo su virtualidad expresiva, a partir de la consolidación de las estructuras regionales de iden- 
tidad grupal y colectiva, dichos referentes tomarán el ámbito educativo y escolar como el medio idóneo para su conservación y reproducción.

Una vez consolidadas las identidades étnicas, la especialización identitaria de los grupos sociales, su diferenciación, impedirá que esa labor de enculturación se lleve de forma homogénea, al menos en cuanto se refiere a algunos de los contenidos culturales aceptados por todos como referentes de identidad colectiva, por lo que trasladarán las funciones de transmisión, es decir de socialización y enculturación de los individuos más jóvenes, a los ámbitos en que estos se ven insertos, principalmente los escolares, dado el tiempo vital que en ellos permanecen.

De este modo, los juegos tradicionales quedarán bajo el auspicio de las instituciones escolares, sin que otros ámbitos, como son los familiares, adopten una labor concertada en el proceso enculturativo, dando paso a que los medios de comunicación, principalmente la televisión, surtan de modelos socializadores que en buena medida colaboran en la desaparición de los juegos tradicionales y los deportes autóctonos, en beneficio de los juegos de consumo y los espectáculos de masas.

Antes de seguir adelante con estas reflexiones acerca del valor identitario de los juegos y deportes tradicionales, es preciso detenernos en una de las experiencias vitales más importantes acaecida en numerosos pueblos de La Rioja, nos referimos a los rites de passage, es decir, al cambio de status de niño a joven, de la sociedad infantil a la sociedad adulta, para de ese modo entender con más objetividad, cómo el ámbito familiar, referente obligado para la adscripción a la sociedad infantil, se ha perdido en nuestra moderna sociedad urbana.

Si la cultura infantil, la de las sociedades infantiles tradicionales, se encuentra en trance de desaparecer es porque su modo de transmisión ha sido perturbado. Las sociedades infantiles tenían un status definido por marcadores temporales relativos a la edad, en la cual se distinguían las diferentes categorías de críos (por aquello de que ya están criados), mocetes y chavales, distinguiéndose cada una de las cuales por distinciones en el vestido, la alimentación, las actividades o la división escolar y los juegos. El cambio de status de niño a joven, tiene como elemento más significativo la entrada en la asociación de mozos o mocería, constituyéndose en el rito de paso más importante para abandonar y separarse de la sociedad infantil.

Algunos actos simbólicos presidían esta separación o abandono de la sociedad infantil: por ejemplo el paso de cuadrillas mixtas de una sociedad infantil que no distingue por el sexo a sus componentes, a cuadrillas encuadradas por el sexo: las mocerías. Otro hecho simbólico nos lo ofrece el paso de chaval a mozo, es decir del estado de individuo no considerado socialmente (no se le considera niño, pero tampoco se le considera adulto), al estado de ser sobreconsiderado (teniendo en cuenta la fuerza social que poseía el grupo de mozos o mocería).

Y si encontramos la fase de separación, también se da la fase liminal de todo rito de paso. El último en entrar mozo debía pagar la quintada o convite y permanecía con el cargo de alguacil hasta que entraba otro mozo; pues bien, el alguacil no participaba en plenitud de las actividades de la mocería, ya que era el encargado de todos los menesteres que el alcalde de mozos le ordenaba.

Al margen de las bromas a que era sometido, sobre todo las que ponían a prueba su virilidad, debía estar siempre dispuesto para realizar encargos que de algún modo confesaban tener un cierto carácter humillante, de prueba. Es decir, el alguacil perte- 
nece a la mocería, pero no es un mozo completamente; no es un chaval ni es un mozo; no tiene personalidad, no porque no tenga, sino porque no debe mostrarla (obediencia del mozo más joven al mozo viejo), así, hasta que otro alguacil viene a sustituirlo y sale de ese status marginal, de esa zona liminal del rito de paso, para entrar en la situación estructural de integración plena en el grupo de mozos.

Tal como apunta Leach ${ }^{3}$, estos ritos iniciales de separación dan como resultado apartar al iniciado de la existencia normal; éste se vuelve temporalmente una persona anormal, existente en un tiempo anormal.

Con la incorporación a la mocería no sólo se da el tránsito del status de chaval al de mozo, sino el tránsito de persona dependiente del círculo familiar a persona capacitada para formar él mismo su propio círculo familiar, pues entra de lleno en el periodo de búsqueda de pareja (acceso a los bailes, paseos y rondas donde se puede dar el contacto con el otro sexo), con miras al matrimonio, siguiente rito de paso.

Para las mujeres, el rito de paso, la transición de chavala a moza, se da en el hecho de ir al baile, de ser rondada o deseada y de salir a pasear por las afueras del pueblo. Ir al baile, que generalmente se celebraba en una de las casas de los mozos y en contadas ocasiones, especiales por otra parte, en la plaza, resultaba para la chavala el acto más significativo de cambio de status. A pesar de la vigilancia que ejercían las madres y a pesar de ser un acto público sancionado moralmente, la moza adquiría la independencia suficiente respecto al círculo familiar como la que podía notar el chaval al adquirir el status de mozo; es decir pasaba de ser una persona dependiente del círculo familiar, para denotar la independencia, para recrear un nuevo círculo familiar

El pasear por las afueras, por las calles o por la carretera, simboliza también el alejamiento del núcleo familiar. Las calles, los caminos y la carretera separan poblaciones, casas, pero también unen a miembros de esas casas, de esas poblaciones. Esa ambigüedad de la calle en la que el control familiar se pierde, significa para la joven la adquisición de autonomía, bien para alejarse, bien para quedarse; en cualquier caso, da el paso significativo para separarse de lo que ha cons ${ }^{+i t u i d o ~ s u ~ p u b e r t a d: ~ l i g a-~}$ zón con la casa, con la familia.

Esta referencia de las sociedades infantiles al ámbito familiar, a la casa familiar, se ha visto sustituida o reemplazada por los ámbitos escolares. La socialidad infantil se ve inscrita en el centro escolar que marcará los referentes para su despegue juvenil y el de la cuadrilla de amigos. Tan sólo en determinados contextos culturales, el medio familiar sigue siendo el principio referencial en la formación de la socialidad infantil.

Sabemos que la herencia social y el capital cultural heredado, introducen adecuadamente al niño en el medio cultural al que pertenece; que todos los juegos tradicionales pueden ser considerados como bienes culturales, y que la transmisión de estos bienes culturales sólo se puede dar, si en el ámbito familiar aparecen personas que desempeñen el papel de transmisores; es decir, personas que suministren modelos, reciten rimas y canciones infantiles, cuenten historias, etc. No olvidemos, al respecto, las estrechas relaciones existentes entre folklore infantil y tradición oral.

Sin embargo $y$, hasta una época reciente, si bien los niños pequeños fueron demasiado poco solicitados por la cultura escrita (salvo la de los libros de lectura escolar),

3. Edmund Leach, "Replanteamiento de la Antropología". Seix Barral, Barcelona 1972. 
y por los medios de comunicación, en la actualidad la cultura de la imagen comienza a solicitar la atención de los niños desde la primera infancia y, la observación de los juegos de los pequeños, revela a las claras que son los medios masivos de comunicación los que les suministran sus historias y sus modelos (que cambian además con cada serie televisiva).

La función de transmisión, de socialización, se encomendará a estos dos ámbitos socializadores, el formal o escolar y el informal o de los medios de comunicación, con la carga ideologizadora que presentan en cada contexto. Se trata mucho menos de una revolución de contenidos, que de una revolución del modo de transmisión.

\section{Concepto de juego}

Antes de seguir adelante con esta breve exposición, es preciso que hagamos una nueva parada en el concepto de juego y sus diferentes interpretaciones, a fin de situarnos con mejor bagaje en este debate sobre la utilización del juego tradicional en la práctica educativa.

Numerosos autores dan por seguro que el juego es un fenómeno antropológico, aun cuando su interpretación fenomenológica da lugar a controversias, debido al carácter polisémico de los juegos, es decir, al gran número de significados que posee el juego y la actividad de jugar. El fenómeno del juego no es de ninguna manera transparente ni fácil de comprender, muy al contrario, este fenómeno, que se diferencia de la vida "corriente", ofrece una resistencia sorprendente a la inteligibilidad conceptual cuando se intenta analizar sus estructuras.

Para establecer un principio de acuerdo sobre el concepto de juego, nos serviremos de la definición de Johan Huizinga ${ }^{4}$ que lo expresa como una acción u ocupación libre, que se desarrolla dentro de unos límites temporales y espaciales determinados, según reglas absolutamente obligatorias, aunque libremente aceptadas, acción que tiene su fin en sí misma y va acompañada de un sentimiento de tensión y alegría y de la conciencia de "ser de otro modo" que en la vida corriente. Esto último es así, porque en todas partes se encuentra la presencia del juego como una cualidad determinada de acción que se distingue de la vida "ordinaria".

Más cercano a nosotros, Moreno Palos ${ }^{5}$, lleva a cabo una aproximación conceptual desde su carácter etimológico y terminológico, acotando definiciones dadas desde diferentes ámbitos científicos y concluyendo que juego, desde el punto de vista conceptual, es aquella actividad que posee las siguientes características:

- Actividad pura o autotélica. Es decir, con finalidad en sí misma.

- Actividad espontánea. De aparición repentina y que no requiere aprendizaje previo.

- Actividad placentera. Entendiendo el término placer en un doble sentido: físico o sensual y "moral" o de consecución de metas.

\footnotetext{
4. Johan Huizinga, "Homo Ludens"(1954), Alianza, Madrid 1972, pags.43-44

5. Cristóbal Moreno Palos, "Juegos y deportes tradicionales en España". Alianza, Madrịł 1992, pag. 15
} 
Las manifestaciones lúdicas, "juegos", son aquellas que poseyendo las características anteriores, reúnen los siguientes requisitos en su desarrollo:

- Actividades limitadas espacio-temporalmente (tiempo y campo de juego).

- Actividades que poseen reglas asumidas voluntariamente, que condicionan el comportamiento del jugador.

- Actividades donde interviene la destreza física, la estrategia y el azar o cualquier combinación de estos elementos.

Al primero debemos la originalidad y la primacía de sus hipótesis y planteamientos, y al segundo sus análisis precisos y conclusivos desde la sociología, la antropología, la psicología o la psicopedagogía, y sin embargo, como se puede observar, ambos autores parecen coincidir en sus aproximaciones conceptuales.

Podríamos enfrentar la definición conceptual que ofrecen estos dos autores con las aproximaciones terminológicas o científicas que se ofrecen desde diferentes ámbitos científicos, aunque me temo que las conclusiones no diferirían de las ofrecidas.

Creo, a este fin, que resultará sumamente provechoso en el futuro, quedarnos con algunas de estas características sobre el juego: actividad espontánea, reglada pero libre, con un fin en sí misma, placentera y que se distingue de la vida corriente.

Hay otra manera de acercarnos al concepto de la actividad lúdica o del juego, y esta manera es el conocimiento de las modalidades o variedades del mismo.

Ahora bien, siempre que se lleve a cabo un trabajo de recopilación de juegos, es preciso, aunque sea de forma arbitraria, como corresponde a todo intento de clasificación, establecer alguna tipología identificativa.

Si atendemos a las categorías de la actividad lúdica, la clásica división de Roger Caillois, es el prolegómeno necesario de toda clasificación tipológica pues se considera que proporciona el instrumento para elaborar "una sociología a partir de los juegos", ya que fragmenta y disloca artificialmente lo que la experiencia corporal unió íntimamente: el vértigo visceral, la mímica de la apariencia, la fuerza agonal y la incertidumbre del azar.

Tras examinar las diferentes posibilidades, Roger Caillois ${ }^{6}$, propone con este fin, una división en cuatro apartados principales según que, en los juegos considerados, predomine el papel de la competición, el azar, el simulacro o el vértigo. Los denomina respectivamente Agon, Alea, Mimicry e llinx. Los cuatro pertenecen al dominio de los juegos: se puede jugar al fútbol, a los bolos o al ajedrez (agon: competición), se juega a la ruleta o a la lotería (alea: azar), se juega a los piratas o a ser Napoleón (mimicry: simulacro), se juega a provocarse mediante rápidos movimientos de rotación o de caída, un estado orgánico de confusión o de descontento (ilinx: vértigo). Sin embargo tales designaciones no abarcan por completo el universo del juego. Lo distribuyen en cuadrantes cada uno gobernado por un principio original.

Se puede colocarlas (las designaciones) entre dos polos opuestos. En un extremo reina un principio común de diversión, de turbulencia que puede designarse con el nombre de "Paidia" (juego irreflexivo). En el extremo opuesto, esta exuberancia traviesa y espontánea es casi por completo absorbida, en cualquier caso disciplinada, por una tendencia complementaria, una necesidad creciente de someterla a conven-

6. Roger Caillois, "Los juegos y los hombres", 1958. 
ciones arbitrarias, imperativas y molestas que designaremos "Ludus" (juego con reglas).

El juego, cuyos impulsos primarios serían muy poderosos se manifestarían también en los demás aspectos de la vida social y cultural, y consecuentemente la diversidad de culturas vendría dada por la selección de esos impulsos primarios que cada cultura hubiera realizado.

Estos impulsos primarios o actitudes elementales que dominan los juegos, son al decir de R.Caillois: "la competición, el azar, el simulacro y la búsqueda del vértigo o el pánico voluptuoso".

Estos principios que pueden darse combinadamente aunque en distintas proporciones, y con un predominio de unos sobre otros, serían los que con su influencia en la cultura determinarían las diferencias entre ellas.

Otra clasificación, también clásica entre los estudiosos del juego, es la de Jean Château' ${ }^{7}$ que al realizar una tipología de juegos, reconoce diferentes categorías de jugadores según sea su edad. Dice que los primeros juegos, los del infante, son juegos sin ninguna regla. La regla aparece con las primeras imitaciones bajo una forma encubierta e inferior, durante el segundo año. Los juegos de regla arbitraria, que se desarrollan a continuación hacia el fin de la edad preescolar y a principios de la edad escolar, conservan de los juegos de imitación y de los de construcción la noción de una regla.

Con la tercera infancia, desde los siete años más o menos, vemos aparecer juegos de un carácter nuevo, los juegos sociales. Los juegos figurativos y los juegos de regla arbitraria pueden ser utilizados ya por un grupo. Pero, sobre todo en los varones, los juegos más en boga en esta época son los de proeza. Cuando llegan a una organización rudimentaria, se convierten en juegos de competición ( $y$ anuncian los deportes individuales).

El fin de la infancia, desde los diez años aproximadamente, ve desarrollarse los juegos de grupo organizado, los juegos tradicionales. Estos juegos nacen de los precedentes. Los juegos de proeza originan en efecto, los juegos tradicionales de competición cooperativa, como el marro, las cuatro esquinas, la rayuela, etc. En estos juegos se podrían distinguir aún aquellos juegos en que cada uno juega por cuenta propia, como la rayuela y las cuatro esquinas, y los juegos más difíciles que comportan equipos (y anuncian los deportes colectivos), como el marro o el juego de policías y ladrones.

Los juegos de imitación, por su parte, originan juegos tradicionales como las ceremonias de las niñitas, en las cuales se juega a algún gran acontecimiento, esponsales, casamiento, batalla.

Finalmente, a las ceremonias hay que agregarles las danzas, en el amplio sentido de la palabra, en las que las evoluciones de las jugadoras implican un vasto grupo y van acompañadas de cantos.

Así pues, Château, observa tendencias distintas entre ambos sexos, propias del componente cultural de su transmisión y que dibujan significativamente el carácter enculturativo y socializador de los juegos populares o tradicionales.

7. Jean Châtedu, "Psicología de los juegos infantiles", Buenos Aires 1973, pags.133 y ss. 
Ahora bien, si las categorías infantiles tienen todos los referentes necesarios para su organización según la edad, también el hábitat o medio en que se desarrollan, el entorno y su ecología, son otros referentes añadidos a la hora de clasificar en tipologías los juegos y deportes tradicionales.

Para todos resulta obvio que jugar es la actividad mejor compartida del mundo. Todo, un objeto, una palabra o el cuerpo pueden servir de soporte a la actividad lúdica.

Se puede jugar en todas partes (el pórtico de las iglesias, los sopórtales de la escuela, el frontón, la plaza, las eras o los descampados; paredes de piedra, calles y hasta el montón de tierra o estiércol, son escenarios naturales para el desarrollo de la actividad lúdica), y no importa con qué (piedras, palos, clavos, cueros, cartones, cuerdas y hasta los animales), pueden servir de vehículo lúdico, de representación simbólica.

Los ritmos de la naturaleza, de carácter cíclico, estacional; las actividades cotidianas y los tiempos de fiesta; el clima con su correspondencia sobre la flora y la fauna determinan otras tantas formas de agrupar los juegos.

Por añadidura, la multitud y la variedad infinitas de los juegos hacen desesperar de descubrir un principio de clasificación que permita separarlos en un pequeño número de categorías bien definidas.

Luis Gracia Vicién ${ }^{8}$, dice que hacer una clasificación de los juegos populares no es tan sencilla como parece. Los juegos son distintos según las edades, sexos, generaciones, tiempos y espacios.

Si los consideramos como actividades tradicionales, los juegos populares se encuentran frecuentemente en el origen de los oficios y en actividades más elevadas, rituales o naturales.

Por otra parte, clasificados en agonísticos o no, estas distinciones se entremezclan constantemente: un juego manual o un juego oral pueden o no ser rituales, pueden ser juegos de destreza, juegos de azar, juegos adivinatorios; incluso juegos de suerte propiamente dichos, que casi siempre son juegos de destreza.

Por tanto, una clasificación teórica de los juegos tradicionales, o el establecimiento de categorías próximas a la función que cumplen, sobretodo fijándonos en su relación con la educación, son vanos y necesarios ejercicios de reflexión sobre el valor del juego como producto de nuestra experiencia y del ejercicio social.

\section{El espacio y los juegos}

Una vez adentrados en el juego como concepto, sería provechoso que nos detuviéramos en realizar algunas observaciones sobre el espacio del juego.

Cualquier juego necesita para su desarrollo de un espacio delimitado; esto es así porque entre las características formales del juego se demarca, material o idealmente, un espacio cerrado, separado del ambiente cotidiano, entendiendo por tal, el ámbito doméstico, el escolar o el de expresión de la sociabilidad.

En ese espacio puntual se desarrolla el juego y en él valen las reglas, porque las reglas se escriben o se aceptan para los espacios delimitados. Son los espacios los que

8. Luis Gracia Vicién, "Juegos tradicionales aragoneses", Zaragoza 1978, pag.13 
establecen la primera regla: sólo se puede jugar en este espacio y no en otro. Quien sale de los límites del espacio sale del juego, deja de ser un jugador y se sumerge en el espacio cotidiano. Los límites no vienen impuestos por las medidas del espacio material, sino por las convenciones del grupo de jugadores, que trazan la primera y principal regla: los límites espaciales.

Así pues, para jugar, partimos de la necesidad de un espacio de juego, pero ¿quién traza los límites y a quién pertenece?.

Para responder a este interrogante debemos entender que acondicionar el espacio es ya darle una función. En su propia casa, los niños no juegan donde mejor les parece sino donde les designan como espacio de juego, donde les dejan, es decir donde le marcan los límites fronterizos de los espacios de no-juego, de trabajo o del mundo adulto, espacios en definitiva con funciones precisas que no poseen las características del espacio de juego infantil. En la escuela, los espacios de juego son asimismo determinados por los adultos que establecen diferentes categorías según sea la práctica del juego, como el patio de recreo, la sala de juegos, los espacios deportivos o de juego grupal y de competición, etc. En la calle, las ludotecas, organizadas por los adultos para los niños, hacen su aparición desde el momento en que el espacio social de la calle deja de ser tal.

También debemos comprender que todo espacio geográfico es un espacio económico. El espacio del juego también tiene una valoración económica. Podemos observar cómo algunos niños burgueses tienen un cuarto de juegos específico, y también como algunos niños de clases más desfavorecidas juegan en la calle o procuran hacerse invitar por compañeros más favorecidos. Y ésta sería la observación primera para una valoración económica, aunque no la principal, porque podríamos dimensionar los cuartos, sumar y valorar los objetos de juego, apreciar la calidad de sus materiales, etc.

Si salimos del ámbito doméstico y familiar y nos trasladamos al espacio en que se desarrollan los juegos en los recintos escolares, observaremos que viene determinado por dos tipos de fronteras, las reales y las simbólicas. Las primeras, las reales, nos indican en general, que las escuelas tienen pocos espacios libres; que los patios de recreo son pequeños, los cobertizos incómodos y los campos de juego son a veces inexistentes. El espacio está siempre dividido por límites rígidos, barreras, rejas, marcas en el suelo pero también con límites sutiles, prohibidos, simbólicos, aquellos que son aprehendidos por el grupo, según normas internas de funcionamiento lúdico.

El juego es como un área donde se adquieren experiencias acerca de la propia intervención modificadora en el medio, donde el ritual de trazado de límites simbólicos, ayuda a la comprensión de uno mismo como un yo actuante, experimentando la comprensión del rendimiento y la satisfacción por la realización de cuantas tareas se había propuesto.

A través del juego los niños se encuentran a sí mismos, aprenden a valorar los resultados de su intervención en el medio, a comprender su actuar, a planificar más allá del momento, a exigirse a sí mismos. Tratan de ampliar por medio del juego su conocimiento del mundo.

Al jugar adquieren experiencia de las cosas y del medio en el que juegan. Así aprenden coordinación y subordinación al grupo infantil y el sentido de cooperación con sus semejantes. Ahora bien, cuando citamos el grupo infantil no nos referimos a 
las sociedades infantiles tradicionales, sino a conglomerados de edades muy diferenciados en el sistema escolar.

La disolución de las sociedades infantiles no está (únicamente) ligada al abandono del espacio rural en beneficio de la vida urbana. La vida urbana no excluye, hasta el siglo pasado, la existencia de las sociedades infantiles. La disolución de estas "sociedades" se debe, sobre todo, al hecho de que "de lugar común", de espacio general de la socialización, la calle pasará a ser un espacio dedicado al cumplimiento de una sola función, consagrado en forma casi exclusiva a la circulación. De territorio habitado pasará a ser territorio atravesado, lugar de tránsito.

Jugar al aire libre sin ser molestado, de acuerdo con sus necesidades, es imposible donde el niño está expuesto a estímulos demasiado fuertes que lo distraen continuamente.

Las calles de una gran ciudad no son un medio apropiado para jugar. Un espacio al aire libre, adecuado a sus necesidades de movimiento y actividad, necesita de suelos de diferente naturaleza, donde las posibilidades de modificación sean explícitas.

Los grupos infantiles escolares no son socializados, su organización es impuesta desde el exterior y no existe en el interior de ellos la transmisión de ningún saber (salvo cuando son mezclados en los patios de recreo). Los niños reciben en el espacio escolar cultura y organización.

Los niños ya no dominan su formación, como no dominan el espacio. Están allí en tanto que colección de individuos. El espacio escolar y el espacio familiar son espacios no-productivos, mas bien reproductivos. El niño no está, por lo tanto, en contacto con las técnicas vigentes en la sociedad. No encuentra ya a su libre disposición, una variedad de materiales aptos para el juego, sino que debe conformarse con aquellos cuidadosamente controlados que recibe. Su intervención en el medio es por tanto una intervención controlada, organizada, delimitada por los fines y objetivos que el mundo adulto considera de utilidad social, de provecho.

\section{La actividad lúdica}

Volvamos nuevamente ahora, sobre lo antedicho acerca de la actividad lúdica y el proceso de enculturación. Huizinga ${ }^{9}$ nos advierte que la actividad lúdica es la fuente misma de la cultura. Quien examine la función del juego en la cultura, encuentra el juego en la cultura como una entidad dada, existente antes de la propia cultura, acompañando a esta y marcándola con su impronta desde el origen hasta el estadio de cultura en el que él mismo vive. Se encuentra en todas partes la presencia del juego como una cualidad determinada de acción que se distingue de la vida "ordinaria". Lo que nos interesa, es precisamente esa cualidad, tal como se presenta en su peculiaridad, como forma de la vida que denominamos juego. Su objeto es, pues, el juego como una forma de actividad, como una forma llena de sentido y como función social.

$\mathrm{Si}$ nos adentramos en esa propuesta recurrente del juego como forma de actividad y como función social, ligándola a los objetivos educativos actuales, se trataría de

\footnotetext{
9. J. Huizinga, 1972, pag.15
} 
observar el proceso de socialización que se da en la escuela como un proceso de enculturación del mundo adulto sobre el mundo infantil. En este sentido, considero que se enseña las reglas que imperan en la relación social a costa de la tergiversación del juego como fuente de actividad lúdica, de revolución del mundo adulto.

La escuela, al funcionalizar el juego, al reglamentarlo, al buscar un provecho sea cognitivo, empírico, o de regla social, está acabando con la subversión lúdica que significa el juego libre y espontáneo, el juego popular tradicional.

Dado el desarrollo del mundo del juego ${ }^{10}$ a través de programas u objetivos realizados por adultos, es necesario manifestar la distinción entre juego espontáneo (actividad lúdica) y propuesta de juego (actividad ludiforme); mientras que en la primera es el niño el protagonista del juego, quien desea, crea, imagina, hace o deja de jugar si le apetece, en la segunda el niño es como invitado por el adulto, un participante que sigue pero no marca caminos, ni siquiera elige reglas, compañeros, lugar o tiempo, uniéndose a esto los fines (pedagógicos o deportivos) que pretenden su desarrollo.

Además, si observamos el juego como toda ocupación que no tenga otra finalidad en sí misma, nos enfrentaremos al carácter funcional y de utilidad que se da en los centros escolares. Quien se esfuerce por introducir en el juego infantil, nada más que fines educativos, demuestra no comprender la esencia misma de toda actividad lúdica. Frente al carácter de utilidad, es una característica del juego que mucho de lo que en él sucede sea "gratuito". También lo es que el resultado con frecuencia no esté en proporción alguna con el empleo de la fuerza y tiempo que el juego requiere.

Decimos que jugando, el niño aprende a hacer algo que tiene su fin en sí mismo y mediante esa experiencia vital, el niño, cuando adulto más tarde, puede comprender que la cultura también tiene su fin en sí misma, que existen valores ajenos a toda utilidad práctica y que el ser humano puede entregarse a un ideal, sin por ello derivar consecuencias de utilidad o provecho.

Es el caso de los ejercicios a los que se dedica el niño. Si de ellos resulta con frecuencia un aprendizaje "funcional", son sin embargo buscados por sí mismos, sin la intención del fin que permiten conseguir.

En el juego, el niño ejercita su agilidad física, sus sentidos, sus representaciones y su pensamiento, y tiene valor incluso en los casos en que el educador no puede reconocerle ninguna utilidad evidente.

Dice Huizinga ${ }^{11}$ que en nuestra conciencia, el juego se opone a lo serio. Esta oposición permanece, al pronto tan inderivable como el mismo concepto de juego. Pero, al considerarla de cerca, esta antítesis juego-gravedad no nos parece ni concluyente ni sólida. Podemos decir: el juego es lo no-serio. Pero además de que este juicio no dice nada al sujeto sobre los caracteres positivos del juego, es muy inestable. En cuanto modifiquemos la proposición precedente para decir: el juego no es serio, ya nos traiciona la antítesis, pues el juego puede ser muy bien algo serio. Por lo demás volvemos a encontrar inmediatamente diversas categorías fundamentales de la vida alineándose también en lo no-serio, sin por ello equivaler al juego.

10. Juan y Modesto Martín Cebrián, "Juegos infantiles", Valladolid 1986, pag.3

11. J. Huizinga, 1972, pag. 17 
La actividad lúdica parece pues infiltrarse en nuestras actividades "serias", modificando sus modalidades de ejecución. Esta observación basta para mostrar que la distinción entre juego y trabajo, o entre juego y seriedad, no es pertinente. Por eso decimos revolución del mundo adulto, subversión del mundo adulto, porque la actividad lúdica penetra las actividades del adulto modificándolas, transformándolas, en clara oposición al principio de orden y regla social, que en sí misma tiende a la inmanencia, a su perpetuación.

Acerca del valor educativo del juego ${ }^{12}$, tan encomiado por los pedagogos, quizás sea suficiente con señalar lo dicho por Ferenczi: "El juego es un modo universal de disfrute humano y la manera más agradable de adquirir conocimiento, ya que por este medio, el individuo obtiene una visión de conjunto, una configuración, hasta incluso adquirir con éste el hábito de realización de sus posibilidades"; pero al mismo tiempo no habrá que olvidar que el juego aparece como educación sin un fin específico, porque precisamente su atractivo está en ser opuesto al trabajo. Este distanciamiento del juego con respecto al trabajo ${ }^{13}$ se presenta también como una garantía para su eficacia, de la misma forma en que lo serio del trabajo se instaura eliminando el espíritu de juego. En este sentido, cuanto más alejado de la realidad se halla el juego, tanto más grande es su valor educativo. Porque no se trata de aprender recetas sino de desarrollar aptitudes.

En efecto, la distancia existente entre mundo adulto y mundo infantil está en correspondencia con la distancia existente entre trabajo y juego, o entre reglas y normas sociales y actividad lúdica; sin embargo, esta distancia es también una garantía de eficacia. Cuanto más alejado de la realidad se halla el juego, la realidad social del adulto, la realidad del proyecto educativo de los centros escolares con sus objetivos utilitarios e interesados, más grande es su valor educativo.

No se trata de aprender normas de incierto cumplimiento, sino de desarrollar actitudes y valores que favorezcan la inserción del joven en el mundo social del adulto. El cambio de actitudes y motivaciones debe ser la base de toda educación encaminada a lograr igualdad de oportunidades. Para tal fin, si bien el juego no es el único camino, nos ofrece muchas posibilidades.

Porque, recordemos, aunque el juego es libre, intenso, placentero y creador, su objetivo es el juego mismo, y si lo convertimos en algo obligatorio o carente de satisfacción, estaremos encontrando nuevas formas de trabajo pero habremos acabado con el juego y con su capacidad educativa. El juego escolar, el juego en las aulas y en los patios de recreo, debe encontrar el punto de ensimismamiento y placer que lo libere de las cadenas del trabajo productivo, si queremos que este tenga el carácter formador y educativo, que el tutor, maestro y pedagogo objetiva en su quehacer diario.

La vivencia de libertad está determinada por el hecho de que el niño que juega se deja guiar por su propia necesidad, y sólo por ella, mientras que el hombre que trabaja obedece a una necesidad que le es impuesta desde afuera. Mientras el juego en

12. Rodríguez Becerra, S. y Marcos Arévalo, J., Introducción a "Juegos infantiles de Extremadura " de Hernández de Soto, S., Jerez de la Frontera, 1988, pag.15

13. Voirin, M., "¿Qué es el juego?". UNESCO, París 1979, pag.140 
el niño es una actividad carente de finalidad utilitaria, el trabajo del adulto es una actividad dirigida hacia un fin inmediato.

Ahora bien, el mundo de los niños existe sin duda, pero está lejos de ser un mundo cerrado a las influencias del medio y a las de los educadores. Si el medio en que se desarrolla el juego es principalmente el medio escolar, dada la limitación y delimitación de los espacios de ocio y tiempo libre, será preciso que tomemos en consideración la influencia que ejerce el educador, el pedagogo, como representante de la autoridad del adulto y como mediador entre el mundo social del adulto y el mundo infantil.

Todo juego es una actividad carente de fin, posee finalidad en sí misma, pero es a su vez una actividad ordenada, sometida a regla y, por tanto, en la que puede intervenir un factor formativo o educativo. $Y$ es en este factor formativo o educativo, donde el educador o el pedagogo interviene como autoridad, pudiendo transformar la realidad lúdica, la realidad de la subversión lúdica, acomodándola a sus necesidades personales o a sus objetivos de control formativo.

Porque aunque no se trate de eliminar el carácter subversivo que posee la actividad lúdica para con la autoridad del adulto, sí se tratará de contenerla, de normalizarla e integrarla. Es decir, el pedagogo o el educador, buscará la ritualización e institucionalización de la actividad lúdica en el ámbito educativo integrándola. Buscará la acomodación y domesticación de la actividad lúdica, de la actividad imprevisible e incongruente, mediante el control disciplinado y reglado de la actividad educativa.

A veces, este control, esta contención de la actividad lúdica, puede verse desbordada (imagínense los alborotos escolares), por la intensidad del juego o por las manifestaciones fantasiosas e irreales de los jugadores. Por ello, el pedagogo no tratará de acomodarse a la actividad lúdica, ya de por sí desbordante para aquel que no participa en la misma, sino que buscará su acomodo en la práctica educativa.

No siempre ${ }^{14}$ los niños encuentran plena satisfacción en el juego y en el cumplimiento de las tareas que la escuela les impone. Su deseo de "realizar un trabajo verdadero" no se cumple si no se les explica el contexto en que desarrollan ese trabajo, de tal suerte que su quehacer adquiera un sentido para ellos. Así, también, para preservar su buena disposición al trabajo, hay que concederles independencia en su ejecución.

Por otra parte, el valor didáctico de un juego depende de la intención del educador de beneficiar a los niños de una manera determinada; del interés que el juego despierte en los niños, el cual es una condición para que aprendan, y de las posibilidades de acción que un juego ofrece.

Desde un punto de vista práctico, la actividad lúdica sigue siendo -incluso bajo control- un dispositivo culturizante fundamental. Lo que conviene mencionar entonces, son los límites de las acomodaciones con el juego.

Como fácilmente puede comprenderse, el ocio, los espectáculos y la propia pedagogía son campos especializados en la acomodación con el juego. Los mundos del

14. Hildegard Hetzer, "El juego y los juguetes". Buenos Aires 1978, pag.19 
ocio y del espectáculo responden a esta exigencia de control. El juego en ellos está civilizado.

El ocio es una forma de aliviar las tensiones producidas por el trabajo o la obligación cotidianos, y el espectáculo tiene por finalidad desposeer al hombre del juego, representando el juego ante él. Es el caso del teatro como del deporte.

El juego ${ }^{15}$ es una de las formas básicas en que se verifica el enfrentamiento del ser humano con su medio. Si el hombre adulto no encara su trabajo como un juego, eso se debe a que se halla bajo la coacción de una inexorable necesidad vital. A diferencia del juego, cualquier trabajo -casi siempre fuente de preocupaciones-, es dirigido a un fin inmediato.

Partimos de que las manifestaciones del juego no son inocentes como parece designarse al mundo infantil; su propia identidad, como actividad libre, espontánea y placentera, y en la que se adquiere conciencia de ser de otro modo, de una actividad no corriente o que se distingue de la actividad ordinaria, está en clara contradicción con las manifestaciones de la educación, tomada como una actividad obligatoria, organizada y en numerosas ocasiones nada placentera, en la que se adquiere conciencia de ser uno más del conjunto aula o centro, y que se distingue por ser una actividad corriente y perteneciente a la vida ordinaria o cotidiana.

Además está el otro, el adulto pedagogo para el niño, que puede entrar en la escena de la actividad lúdica, pero para desnaturalizar el juego, al imponer normas, reglas, procedimientos, orden, disciplina, etc. Porque no olvidemos que la disciplina es algo consustancial a la enseñanza. Ningún proceso educativo, ningún aprendizaje, resulta exitoso sin disciplina.

La disciplina a su vez no es neutral, pues responde a los intereses del pedagogo, que a su vez está inserto en otra disciplina, la de la institución educativa que le acoge y establece sus propios intereses pedagógicos.

Pierre Bourdieu ${ }^{16}$ comenta cómo en su famoso libro Homo Ludens, Huizinga afirma que, mediante una falsa etimología, se puede hacer como si illusio, palabra latina que proviene de la raíz ludus (juego), significara estar en el juego, estar metido en él, tomarse el juego en serio. La illusio es el hecho de estar metido en el juego, cogido por el juego, de creer que el juego merece la pena, que vale la pena jugar. De hecho la palabra interés, en un primer sentido, significaba precisamente esta noción de illusio, es decir el hecho de considerar que un juego social es importante, que lo que ocurre en él importa a quienes están dentro, a quienes participan. Interesse significa "formar parte", participar, por lo tanto reconocer que el juego merece ser jugado y que los envites que se engendran en y por el hecho de jugarlo merecen seguirse; significa reconocer el juego y reconocer los envites.

Retomando la explicación de Bourdieu, los intereses del pedagogo o los intereses de la institución educativa, equivaldrían a la participación en el juego pedagógico y en el juego de la enseñanza y en la validez de su reconocimiento por el niño, adolescente o joven, cuyos intereses o modo de participación son diversos, pues participan del juego del aprendizaje, donde la illusio por aprender, depende en buena medida de la

15. Hildegard Hetzer, "El juego y los juguetes". Buenos Aires 1978, pag.10

16. Pierre Bourdieu (1994), "Razones prácticas. Sobre la teoría de la acción", Barcelona 1997. pag. 141 
capacidad del juego pedagógico que despliegue el pedagogo o el educador. En esta conjunción de intereses se formaliza el binomio enseñanza aprendizaje.

La pedagoga alemana Hildegard Hetzer ${ }^{17}$ advierte que la iniciación de todo juego requiere de los niños la ejecución de ciertas acciones. Primero, los niños deben aprender muchas de esas actividades para luego perfeccionarlas mediante el ejercicio. Jugar y aprender constituyen una unidad inseparable.

No hay contradicción alguna entre jugar y aprender. Todo depende de que a los niños se les ofrezca un área de juego que les brinde la oportunidad de aprender lo pedagógicamente deseable y de que se les estimule a enfrentarse con lo ofrecido. La ayuda que debemos brindarles hà de interpretarse como guía de su juego libre mediante ofrecimientos de aprendizaje e incentivos para aprovecharlos.

Todo lo que los niños aprenden en este sentido por medio del juego, igual que los conocimientos y habilidades que por él adquieren, luego to transfieren a la vida.

Ya en 1922, el psicólogo John Dewey ${ }^{18}$ consideraba el juego como una actividad positiva en sí misma, y lo que es más importante, como un instrumento didáctico muy valioso. El propone que los juegos deben ser considerados como una parte del curriculum y no simplemente como una forma de romper el tedio del trabajo escolar. Según la teoría de Dewey, tanto "el trabajo" como el "juego" son procesos activos y por ello conducen al aprendizaje. La diferencia entre uno y otro estriba en que el juego es una actividad que tiene finalidad en sí misma, mientras que el trabajo conduce a metas externas. Esta diferencia lo que pone de manifiesto es una ventaja del juego sobre el trabajo más que un inconveniente, desde el punto de vista didáctico, si lo analizamos en términos de motivación.

Resulta mucho más fácil motivar a los niños cuando están aprendiendo cosas por medio de una actividad que al mismo tiempo les divierte. Esta buena disposición facilita el aprendizaje y despierta un gran interés por los contenidos que se transmiten en el juego.

La creatividad infantil se expresa por su capacidad para asimilar los objetos del aprendizaje. Si los juegos expresivos son los primeros en suscitar creaciones, es porque implican inmediatamente la contribución de otro y porque reciben su objetividad indispensable. El otro es necesariamente el adulto en el proceso de socialización, pero en el juego puede ser perfectamente el compañero o el amigo, aquel que en definitiva reconozca su valía, en el empeño por confirmarse y distinguirse. En cuanto a las creaciones, siguen estando muy estrechamente inspiradas por los modelos encontrados o por las directrices recibidas del adulto. Fernando Sabater ${ }^{19}$ observa que una de las principales tareas de la enseñanza siempre ha sido promover modelos de excelencia y pautas de reconocimiento que sirvan de apoyo a la autoestima de los individuos. Entrar en cualquier comunidad exige internarse en una espesura de ponderaciones simbólicas: algunos sociólogos, destacadamente Pierre Bourdieu, han estudiado la compleja búsqueda de la distinción que preside el intercambio social y que orienta significativamente también las formas educativas.

17. Hildegard Hetzer, "El juego y los juguetes". Buenos Aires 1978, pags.8 y 9

18. John Dewey (1922). Citado por Martín, E. "Los juegos de simulación en EGB y BUP", Madrid 1982 , pag. 53

19. Fernando Sabater, "El valor de educar", Barcelona 1997, pag.53 
A través del juego, los niños interiorizan paulatinamente el mundo circundante. Es importante que les posibilitemos el acceso a ese mundo y les facilitemos su interiorización. Esto se logra, ante todo, si los adultos permiten que los niños participen en sus vidas en cuanto sea provechoso para ellos. Toda la evolución ulterior de un niño depende en gran medida del correcto aprovechamiento de su capacidad de aprender. Sin embargo, las posibilidades de aprender que tienen los niños dependen de las oportunidades de aprender jugando que se les ofrezcan.

Estas oportunidades tienen su base en la socialización primaria del niño, la que se produce en el entorno familiar, de ahí la importancia que toma el juego en dicho ámbito, ya que en la familia encontramos nuestros primeros modelos de imitación, nuestros referentes morales y sociales. Sobre la importancia de esta socialización primaria y su relación con la capacidad de aprendizaje posterior no es preciso que nos extendamos ahora. Tampoco nos extenderemos sobre las relaciones de aprendizaje en relación al origen social de los niños, observadas con acierto por Bourdieu o Bernstein. Tan sólo haremos hincapié en que el juego en la tarea del aprendizaje es básico para la universalización de la enseñanza y la superación de las desigualdades educativas y los déficits culturales.

Como aprecia el filósofo Fernando Sabater ${ }^{20}$, si el juego es aquella actividad supremamente libre que niega toda instrumentalidad y que el niño busca por sí misma sin que nadie deba imponérsela como obligación, ¿qué mejor camino que éste para educarle, a partir no ya de su obediencia sino de su jubilosa colaboración?

\section{Bibliografía}

BARREAU y MORNE, J.J. (1991): "Epistemología y antropología del deporte"(1984), Madrid.

BOURDIEU, P. (1997): "Razones prácticas"(1994), Barcelona.

CAILLOIS, R. (1958): "Los juegos y los hombres", París.

CHÂTEAU, J. (1973): "Psicología de los juegos infantiles", Buenos Aires.

GRACIA VICIEN, L. (1978): "Juegos tradicionales aragoneses", Zaragoza.

GIRO MIRANDA, J. (1990): "Juegos infantiles de La Rioja", Zaragoza.

FERNÁNDEZ DE SOTO, S. (1988): "Juegos infantiles de Extremadura", Jerez de la Frontera.

HETZER, H. (1978): "El juego y los juguetes", Buenos Aires.

HUIZINGA, J. (1972): "Homo Ludens" (1954), Madrid.

LEACH, E. (1972): "Replanteamiento de la Antropología", Barcelona.

MARTIN, E. (1982): "Los juegos de simulación en EGB y BUP", Madrid.

MARTÍN CEBRIAN, J. Y M. (1986): "Juegos infantiles", Valladolid.

MORENO PALOS, C. (1992): "Juegos y deportes tradicionales en España", Madrid.

SABATER, F. (1997): "El valor de educar", Barcelona.

VOIRIN, M. (1979): "¿Qué es el juego?", París.

20. Fernando Sabater, "El valor de educar", Barcelona 1997, pag.102 